\title{
Bio- Modification of Galactomannan Gums Which Extracted From Guar Seeds and Their Rheological Properties
}

\author{
M. A. Ibrahim, A.A.Ragheb, A.Abd-EL Aty, J.I Abd- EL Thalouth, E.E.EL Sayed
}

\begin{abstract}
Galactomannan gum is an importing group of Polysaccharides base, hydrocolloids are high molecular weight polymers and generally used in a growing number of application. at the present work Galactomannan gum which has been extracted from Guar seeds were modified using an ecofriendly and alternative way to the chemical classical modification using an enzymatic modification by Laccase enzyme, Cellulase enzyme and Brewer yeast this was by rheological properties of the prepared gum were measured as well as the native gum in addition to different storage time also for both modified and un modified guar one.

Key words:,Brewer yeast,Cellulase, Enzyme,Guar ,Laccase.
\end{abstract}

\section{INTRODUCTION}

Polysaccharides based hydrocolloids are high molecular weight polymers generally used as thickening or gelling agent in food, textile printing and other industries.

Galactomannan is an important group of Polysaccharides hydrocolloids, are produced in certain plants as cell wall and storage Polysaccharides.

Industrial application of galactomannan arise due to their interactions with molecules, a large group of Galactomannan is produced from seeds of leguminoseae family ${ }^{(1)}$. They are composed of mannan backbone linked seeds, are composed of mannan backbone linked together by B-(1-4) glycoside linkages and having galactose side chain residues linked by

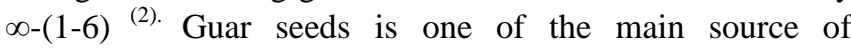
Galactomannan with galactose: mannose ratio $1: 2$, the main features of guar poly galactomannan that make it versatile material for industrial uses are essential the following :good solubility in water, high chemical reactivity and high viscosity at low polymer concentration native and chemical modified guar gum finds wide range of application especially as a emulsion stabilizer ${ }^{(3)}$. As it was remarkable that the trend worldwide is to use an ecofriendly materials. From this aspect at the present work enzymatic modification has been applied on guar gum. Three main types of enzymatic reaction can be

M.A.Ibrahim,printing \& dyeing and finishing textiles,Helwan University/ Faculty of applied arts,Cairo, Egypt

A.A.Ragheb,Textile Research Division, National Research Centre, Cairo,Egypt

J.I.Abd-ELThalouth, Textile Research Division, National Research Centre,Cairo,Egypt

A.Abd-EL Aty, Textile Research Division, National Research Centre, Cairo,Egypt

E.E.EL Sayed, Textile weaving, Industrial development authority, Cairo,Egypt applied to guar gum. A-Deploymerization with hydrolysis enzymes.

B-Degalactolsylationwith $\alpha$-galactosidase,C-Oxidation with redox enzymes ${ }^{(4)}$.

At the present work both depolymerization enzymatic reaction were applied on guar gum using Cellulase as a type of hydrolysis enzyme with two concentrations, studying the rheological properties and the storage and validity time effect on the guar gum and oxidation enzymatic reaction with laccase enzyme.

Procedure for Paper Submission

\section{Materials and methods:}

1.2 Plant Seeds: Dry clean Guar was cultivated in Egypt, provided by Hraz Agricultural Seed \& Medical Plants Company, Cairo, Egypt.

\subsection{Enzymes:}

The following enzymes were selected and used throughout the present work:

1.3.1- Cellulase enzyme: (EAPS 2000) were supplied by Glory chemicals Company, Cairo, Egypt.

1.3.2- Brewer Yeast: were supplied by the Egyptian starch and detergent company, Cairo, Egypt.

1.3.3- Laccase enzyme: (Lava Zyme Lite 1540) were supplied by Egypt office of Dye star company, Cairo, Egypt.

\section{METHODS}

2.1- Extraction of the gum: For the separation of the Galactomannan gum from the aforementioned seeds, the endosperm was thoroughly separated from the hull and the germ. The procedure adopted was carried out as follows:

- The clean dry seeds were crushed mechanically.

-The crushed seeds were sieved to remove the germ which possesses the lowest hardness from the other components.

-The remaining parts which comprise the endosperm and hull are soaked in water over night to allow the endosperm which is composed mainly from Galactomannan gum to swell.

- The swelled gum was isolated from the hull via filtration using a very fine silk fabric.

- The gum was precipitated from viscous solution by adding ethyl -alcohol, filtered and finally air dried, grinded to affine powder ${ }^{(5)}$.

\subsection{Enzyme preparation:}

\subsection{1-Laccase enzyme preparation:}

Laccase enzyme (Lava zyme lite 1540) were applied at powder form directly with two different concentration (300 
gm, $500 \mathrm{gm})$ under optimum condition of the enzyme (PH $=5-5.5$, temp $65^{\circ} \mathrm{C}$, time 20-30minutes) .

After extraction of the gum from fenugreek) seeds the oxidation of Galactomannan by Laccase enzyme was conducted as follows:

$250 \mathrm{gm}$ from Fenugreek gum paste at concentration of $2 \%$, was added gradually to the laccase enzyme during mechanical stirring.

\subsection{2-Cellulase enzyme preparation:}

Cellulase enzyme (EAPS200)were applied at solution form directly with two different concentration(200gm ,400gm )under optimum condition of the enzyme (ph.=4.5-6,temp $\left(55^{\circ} \mathrm{C}-60^{\circ} \mathrm{C}\right)$ time $20-45$ minutes $)$.

After extraction of the gum from Guar seeds the modification of galactomannan by Cellulase enzyme was conducted as follows:

$250 \mathrm{gm}$ from Guar gum paste at concentration of $2 \%$, was added gradually to the Cellulase enzyme during mechanical stirring.

\subsection{3-Brewer's yeast preparation:}

450 gm of dry Brewer's yeast was pasted with 150 gm sugar and then one liter of warm water at $40 \mathrm{c}$ was added to the paste of yeast while stirring for a period of time until the yeast brewed. After extraction of the gum from fenugreek) seeds the modification of Galactomannan by Brewer's yeast was conducted as follows:

$250 \mathrm{gm}$ from Guar gum paste at concentration of $2 \%$, was added gradually to the Brewer's yeast during mechanical stirring ${ }^{(6)}$.

\section{REHEOLOGICAL MEASUREMENTS}

$\mathrm{U}$ The rheological properties of the prepared pastes were measured using a rotary viscometer (Rheomat-15, zurish, Switzerland).

The rheomat viscometer consists principally of two co-axial cylinders. The inner one is axially connected to a motor and can rotate with 15 speeds. The other one is kept stagnat. Both cylinders are usually kept immersed in thermostated water - bath at $25.0 \pm 0.1^{\circ} \mathrm{C}$.

The modified Galactomannan paste (Guar) were poured carefully in the vicinity between the two cylinders so as to avoid air inclusion and kept for 15 minutes to obtain the thermostate temperature (7).

- The corresponding apparent viscosity was calculated according to the following equation:

$\mu($ viscosity $)=\tau / D$

$-\mu$ : Apparent viscosity in poise.

- $\tau$ : Shearing stress( dyne.cm) -2

- D: Rate of shear ${ }^{(6)}$

\section{RESULTS AND DISCUSSION}

Study the effect of the Rheological properties of bioModified Guar thickeners based on Galactomannan. Galactomannan gums on both the native form and the modified one are generally used in the form of viscous solutions, it is a must to investigate the rheological properties and he apparent viscosity of these pastes for the aforementioned Galactomannan Gums. For this reason all the examined pastes were prepared as discussed in the experimental section in a concentration of $2 \%$; their Rheological properties were measured using Rheomat-15. The data obtained are represented in Figure (1-3) as shown

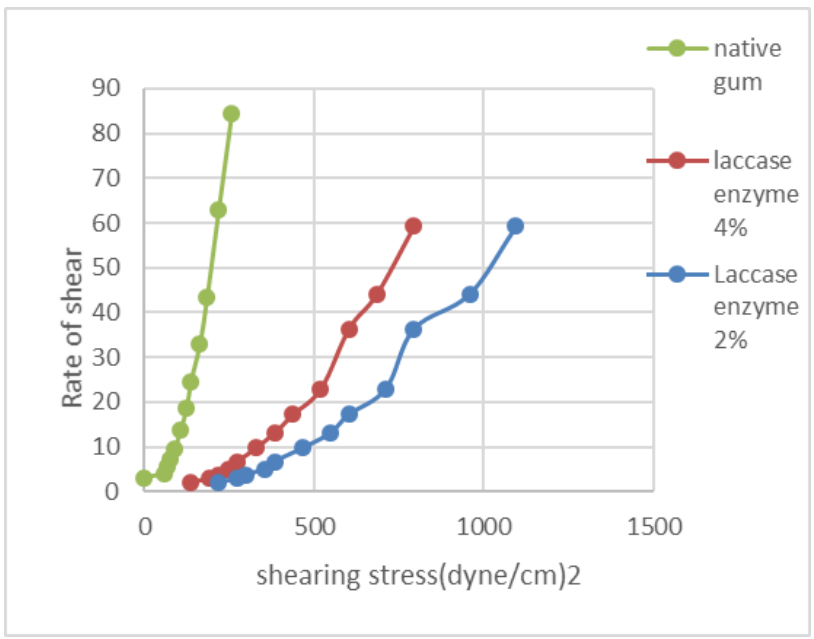

Figure (1): Rheological properties of Galactomannan gums isolated from Guar seeds. Before and after being modified with laccase enzyme with two different concentration

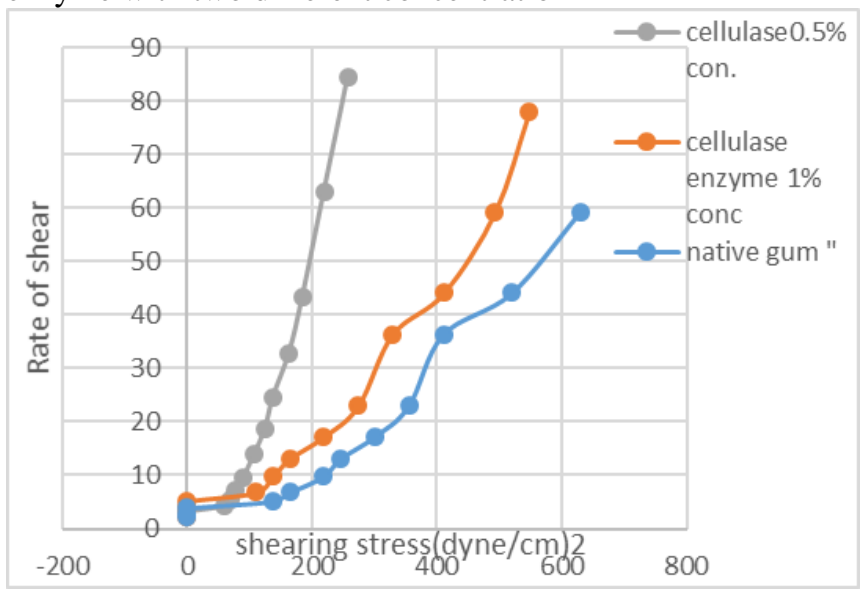

Figure (2) Rheological properties of Galactomannan gums isolated from Guar seeds. Before and after being modified with Cellulase enzyme with two different concentration

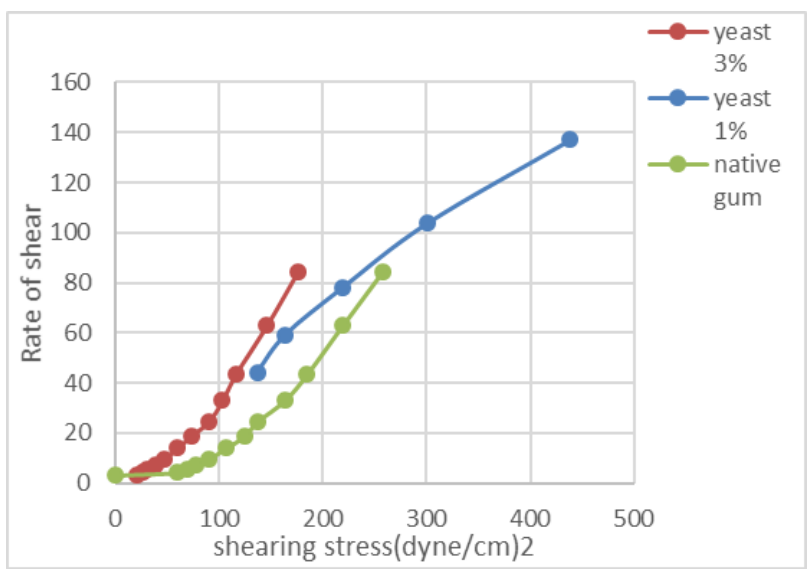

Figure (3) Rheological properties of Galactomannan gums isolated from Guar seeds Before and after being modified with laccase enzyme with two different concentration

As it is clear from the rheogrames of (Figures 1-3) that all 
the examined pastes i.e. modified Galactomannan gums obtained from Guar, as well as native gum are characterized by a non- Newtonian pseudo plastic behavior, this is clear from the relation between shearing stress and rate of shear is not a straight line and concaved toward the rate of shear axis which means if the Pastes are subjected to a large applied force a structural breakdown will happen, which leads the viscosity to decrease. On removing this force, the pastes retain their original viscosity immediately and their rebuilding need no time. It is also clear from the figures above that the enzymatic modification does no effect on the rheological properties of the Guar gum where it is still acquire pseudo plastic behavior.

It is clear from figure (1) that the enzymatic modified Guar Gum using (Laccase) enzymes increases the location of the rheogrames which is shifted far from the rate of shear axis which indicate increase in the apparent viscosity comparing with the unmodified Guar gum.

It is also clear from rheogrames at figures (1and 2) that enzymatic modification using (Celulase, Brewer yeast) causes a decrease in the apparent viscosity of the pastes under investigation.

Table (1) Effect of Laccase enzyme on the apparent viscosity of Guar Gum

\begin{tabular}{|c|c|c|}
\hline \multicolumn{3}{|c|}{ Apparent Viscosity in poise of Fresh Guar Gum on using } \\
\hline $\begin{array}{c}\text { Laccase enzyme } \\
\mathbf{2 \%}\end{array}$ & $\begin{array}{c}\text { Laccase enzyme } \\
\mathbf{4 \%}\end{array}$ & Native Guar Gum \\
\hline 100.4771 & 62.79817 & 0 \\
\hline 93.54288 & 65.48001 & 14.40891 \\
\hline 78.20826 & 56.87873 & 12.51756 \\
\hline 69.2625 & 47.95096 & 10.55257 \\
\hline 56.54521 & 40.38944 & 9.333092 \\
\hline 47.63688 & 33.62604 & 7.709828 \\
\hline 41.7378 & 29.21646 & 6.659776 \\
\hline 34.89919 & 25.38123 & 5.585384 \\
\hline 30.91099 & 22.5888 & 4.971455 \\
\hline 21.82573 & 16.55745 & 4.264291 \\
\hline 21.73016 & 15.52154 & 3.484014 \\
\hline 18.49375 & 13.40797 & 3.052544 \\
\hline
\end{tabular}

As it is obvious from table (1) which study the effect of using two different concentration of laccase enzyme $(2 \%, 4 \%)$ concentration and comparing it with unmodified Guar gum, it was found that the apparent viscosity highly increased as a result of Laccase enzyme modification this phenomena was achieved irrespective of laccase enzyme used for example the apparent viscosity increased from 14.40891poise for the native gum to 93.54288 poise $\& 65.48001$ poise at rate of shear 2.927 for $2 \%$ concentration and $4 \%$ laccase enzyme concentration .this phenomena due to the Laccase enzyme is one of the (oxidoreductose enzymes) which cause an oxidation to the paste and convert it from viscous polysaccharide solution into elastic gel. this is due to the carbonyl groups which generated by the enzymatic reaction which eventually form hemiacetal bonds between generated carbonyl group and free $\mathrm{OH}$ groups causing internal crosslinking of Guar gum and their structuring to yield elastic gels. This phenomena is more pronounced with Fenugreek, Guar gum rather than other Galactomannan gums.as if the primary hydroxyl groups that undergo oxidation are exclusively or preferentially those of the Galactose side chains $^{(7)}$

Table (2) Effect of Brewer yeast on the apparent viscosity of Guar Gum

\begin{tabular}{|c|c|c|}
\hline \multicolumn{3}{|c|}{ Apparent Viscosity of Fresh Guar Gum on using } \\
\hline $\begin{array}{c}\text { Brewer yeast } \\
\mathbf{1 \%}\end{array}$ & $\begin{array}{c}\text { Brewer yeast } \\
\mathbf{3} \%\end{array}$ & $\begin{array}{c}\text { Native Guar } \\
\text { Gum }\end{array}$ \\
\hline 6.911576 & 0 & 0 \\
\hline 6.175245 & 0 & 14.40891 \\
\hline 5.476433 & 0 & 12.51756 \\
\hline 5.276285 & 0 & 10.55257 \\
\hline 4.888763 & 0 & 9.333092 \\
\hline 4.317504 & 0 & 7.709828 \\
\hline 3.904006 & 3.104308 & 6.659776 \\
\hline 3.665408 & 2.874063 & 4.585384 \\
\hline 3.139866 & 2.711088 & 4.264291 \\
\hline 2.677578 & 2.898749 & 3.484014 \\
\hline 2.322676 & 2.195332 & 3.052544 \\
\hline 2.085905 & & \\
\hline
\end{tabular}

As it is clear from table (2) which study the effect of using two different concentration of Brewer Yeast $(1 \%, 3 \%$, ) concentrations and comparing it with unmodified Guar Gum. The apparent viscosity of using Brewer Yeast with (1\%, 3\%) concentration in the modification of Guar Gum, have been slightly decreased for example the apparent viscosity found to be decreased from 3.665408 poise to 3.104308 ) poise by the modification of Brewer yeast which compared to that of the native one which was gum 5.585384 poise at rate of shear 24.36..this phenomena may be due to the Brewer Yeast contains three types of hydrolysis enzymes (amylase, protease, and lipase) and this enzymes may cause hydrolysis actions with the gum which usually involves the transfer of functional groups to water which leads to increase the solubility and decrease the apparent viscosity. 
Table (3) Effect of Cellulase enzyme on the apparent viscosity of Guar Gum.

\begin{tabular}{|c|c|c|}
\hline \multicolumn{3}{|c|}{ Apparent Viscosity in poise of Fresh Guar Gum on using } \\
\hline $\begin{array}{c}\text { Cellulase enzyme } \\
\mathbf{0 . 5 \%}\end{array}$ & $\begin{array}{c}\text { Cellulase enzyme } \\
1 \%\end{array}$ & Native Guar Gum \\
\hline 0 & 0 & 14.40891 \\
\hline 0 & 0 & 12.51756 \\
\hline 10.63942 & 0 & 10.55257 \\
\hline 9.23366 & 8.15578 & 9.733092 \\
\hline 8.41736 & 7.01085 & 7.709828 \\
\hline 7.78201 & 6.52134 & 6.659776 \\
\hline 5.44959 & 5.8884 & 5.585384 \\
\hline 4.45549 & 4.031336 & 4.971455 \\
\hline 3.28917 & 3.312925 & 4.264291 \\
\hline 2.63391 & 2.322188 & 3.484014 \\
\hline 2.085905 & 2.07721 & 3.052544 \\
\hline
\end{tabular}

It is clear from the data at table (3) which study the effect of using two different concentration of cellulase enzyme $(0.5 \%$, $1 \%$ ) concentrations and comparing it with unmodified Guar Gum. It was found that the apparent viscosity on using Cellulase enzyme with both concentration $(0.5 \%, 1 \%)$ in the modification of Guar Gum have been slightly decreased from 9.733092 poise for the native gum to 9.23366 poise \& 8.15578 poise for $0.5 \%$ concentration and $1 \%$ Cellulase enzyme concentration. This phenomena may be due to the Cellulase enzyme and its rule, since Cellulase enzyme is one of the (hydrolyses enzymes) which cause a cleavage to the peptide bonds and the larger molecules are broken down to smaller ones, this type of enzymatic modification, would be a depolymerization enzymatic modification that causes to a various extent decreasesing in the apparent viscosity of the Guar gum ${ }^{(8,9) \text {. }}$

Study the effect of the storage time on the Rheological properties of Galactomannan Gums isolated from Guar seeds as well as its modified form:

One of the most popular drawbacks of the native Galactomannan gum was the rotting of the prepared pastes from which it is must to examine the effect of storing of the prepared modified pastes and compared it with the native one.so the influence of storage and validity time of the pastes on the rheological properties of both enzymatic modified gum as well as the native one were studied below.

All the investigated pastes were prepared in a concentration of $2 \%$; and stored for (1day, and7days, their Rheological properties were measured using Rheomat-15. The data obtained are represented in Figures (4-6).

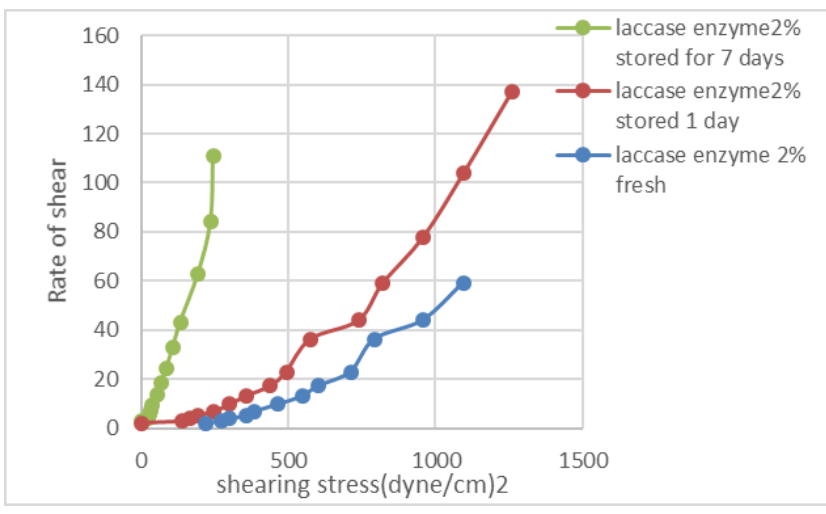

Figure (4) Rheological properties of Galactomananan Gums isolated from Guar seeds modified with Laccase enzyme $2 \%$ conc. at different storage time

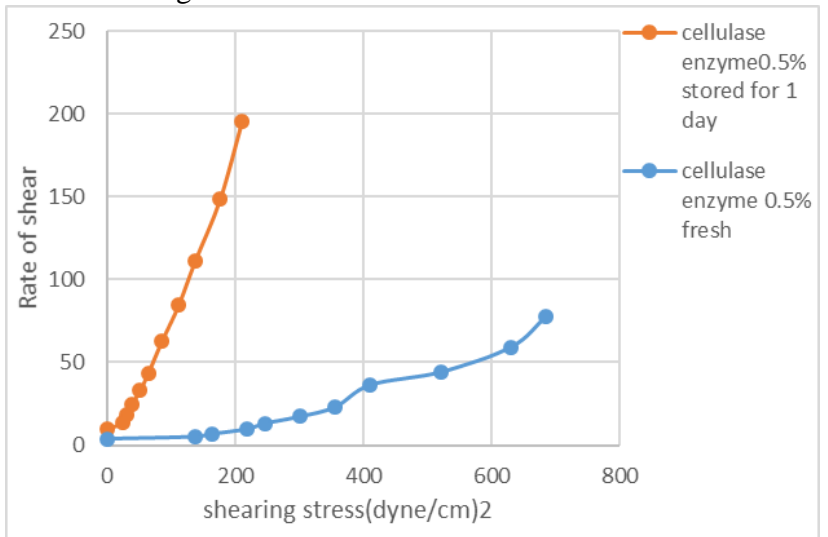

Figure (5) Rheological properties of Galactomannan Gums isolated from Guar seeds Modified with Cellulase enzyme 0.5\% conc.at different storage time.

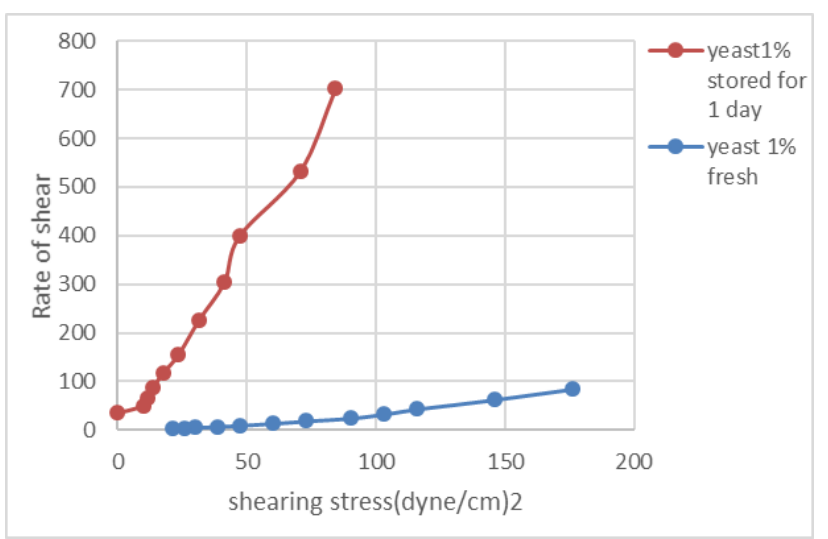

Figure (6) Rheological properties of Galactomnnan Gums isolated from Guar seeds Modified with Brewer Yeast 1\% conc. at different storage time

As it is obvious from the rheogrames of (Figures 4-6), that the relation between shearing stress and the rate of shear is not a straight line which means that all the examined pastes ,as well as native gum are characterized by a non-Newtonian pseudo plastic behavior, since the up and down rheogrames are coincident. This means that, the molecular structure of the pastes is able to rebuild themselves and retain the original state immediately after removal of the applied force.

while it clear from figure (4) while using (laccase) enzyme that the fresh Guar gum rheograme is far from the 
rate of shear axis and as long as the storing time getting longer the rheograme is getting nearer to the rate of shear axis and the rheograme of the examined pastes are following that order from the nearest to the farest of the rate of shear axis (7 days storage, 1 day storage and fresh)which indicate a decrease in the apparent viscosity comparing with the fresh Guar Gum .this is due to that the solubility and the hydrolysis of the paste after it has been stored.

While it is clear from figure $(5,6)$ that the storage time affect the apparent viscosity and that was clear due to the location of the rheogrames which were shifted nearer from the rate of shear axis

Remarkable observation was found when applying cellulase and Brewer yeast to modifying Guar Gum, this was that all examined pastes are rotted after 1 day only storage which leads us to stop the investigation for more storing time

This phenomena was expected since the cellulase enzyme is a hydrolysis enzyme and the brewer yeast contains three types of enzymes hydrolysis enzyme which was easily to rot the enzymatic Guar gum pastes. So the reheograme represents fresh and 1 day storage time only.

For This reason it is not preferred to use Cellulase enzyme or brewer yeast to modify Guar gum. It is also clear from the reheograme that as long as the storage time increased the rheograme is getting nearer to the rate of shear axis which indicate a decrease in the apparent viscosity.

Tables 4and 5 represents the effect of storing time of modified Laccase guar pastes for 1 day and 7 days using two

Concentration of enzyme which were $2 \%$ and $4 \%$ conc.

Table (4) the apparent viscosity of the modified Guar Gum with Laccase enzyme $2 \%$ conc. at different storage time (fresh, 1day and 7 days)

The Apparent viscosity in poise of the Enzymatic modified Guar Gum with Laccase Enzyme 2\%

\begin{tabular}{|c|c|c|}
\hline Fresh & 1day storage & 7 Days storage \\
\hline 100.4771 & 0 & 0 \\
\hline 93.54288 & 46.77144 & 5.146038 \\
\hline 78.20826 & 42.65905 & 4.694086 \\
\hline 69.2625 & 37.29519 & 4.103777 \\
\hline 56.54521 & 36.35049 & 3.999897 \\
\hline 47.63688 & 30.82387 & 3.674359 \\
\hline 41.7378 & 27.12957 & 3.490865 \\
\hline 34.89919 & 25.38123 & 3.270694 \\
\hline 30.91099 & 21.39991 & 3.074256 \\
\hline 21.82573 & 15.80484 & 3.07413 \\
\hline 21.73016 & 13.87031 & 2.798166 \\
\hline 18.49375 & 12.29851 & 2.203624 \\
\hline
\end{tabular}

Table (5) the apparent viscosity of the modified Guar Gum with Laccase enzyme $4 \%$ conc. at different storage time (fresh, 1day and 7 days).

\begin{tabular}{|c|c|c|}
\hline \multicolumn{3}{|c|}{$\begin{array}{c}\text { The Apparent viscosity in poise of the Enzymatic modified } \\
\text { Guar Gum with Laccase Enzyme 4\% }\end{array}$} \\
\hline Fresh & 1day storage & 7 Days storage \\
\hline 62.79817 & 0 & 0 \\
\hline 65.48001 & 0 & 0 \\
\hline 56.87873 & 0 & 0 \\
\hline 47.95096 & 0 & 2.93127 \\
\hline 40.38944 & 6.345307 & 2.666598 \\
\hline 33.62604 & 5.94442 & 2.467145 \\
\hline 29.21646 & 4.515668 & 2.269062 \\
\hline 25.38123 & 4.966893 & 2.224072 \\
\hline 22.5888 & 5.085782 & 2.18173 \\
\hline 16.55745 & 4.216632 & 1.844478 \\
\hline 15.52154 & 3.952839 & 1.831527 \\
\hline 13.40797 & 3.594748 & 1.72122 \\
\hline
\end{tabular}

Table (4 and 5) represents comparison between the different storage times on both pastes treated with using laccase enzyme (2\% and $4 \%$ ) concentration to modify Galactomannan gum. As a contrast of fenugreek gum storage affect the modified guar gum obviously and the apparent viscosity decreased in the case of fresh gum at $(2 \%)$ concentration. For example the apparent viscosity decreased from (93.54288) poise at rate of shear (2.927) to (46.77144) poise at the rate of shear (2.927) in case of 1 day storage, and remarkable decrease in the apparent viscosity to (5.146038) poise at the rate of shear (4.117) while pastes stored for 7 days. And the samples roted before reaching one month storage time.

At (4\%) laccase enzymatic modification for example the apparent viscosity decreased to (40.38944) poise comparing with $2 \%$ laccase enzyme concentration the apparent viscosity was (93.54288) poise.

Also as it mentioned before that the storage time affect the apparent viscosity causing a remarkable decrease in it. For example the apparent viscosity decreased from (40.38944) poise at the fresh form to $(6.345307)$ poise when it stored for 1 day and also the apparent viscosity decreased till it reached (2.666598) poise when it stored for 7 days. 
Table (6) the apparent viscosity of the modified Guar Gum with Cellulase enzyme $0.5 \%$ ) conc. conc. at different storage time (fresh and 1day)

\begin{tabular}{|c|c|}
\hline \multicolumn{2}{|c|}{$\begin{array}{l}\text { The Apparent viscosity in poise of the Enzymatic mo } \\
\text { Guar Gum with Cellulase Enzyme (0.5\%)conc. }\end{array}$} \\
\hline Fresh & 1day storage \\
\hline 0 & 0 \\
\hline 0 & 0 \\
\hline 0 & 1.850359 \\
\hline 16.15578 & 1.837179 \\
\hline 14.01085 & 1.745432 \\
\hline 14.01085 & 1.569933 \\
\hline 12.69061 & 1.388374 \\
\hline 11.88884 & 1.161338 \\
\hline 11.88884 & 1.017515 \\
\hline 9.312925 & 0.966502 \\
\hline 8.322188 & 0.869656 \\
\hline 7.027721 & 0.768855 \\
\hline
\end{tabular}

Table (7) the apparent viscosity of the modified Guar Gum with Cellulase enzyme $1 \%$ conc. at different storage time

\begin{tabular}{|c|c|}
\hline \multicolumn{2}{|c|}{$\begin{array}{l}\text { The Apparent viscosity in poise of the Enzymatic } \\
\text { Guar Gum with Cellulase Enzyme (1\%)conc. }\end{array}$} \\
\hline Fresh & 1day storage \\
\hline 0 & 0 \\
\hline 0 & 0 \\
\hline 26.63942 & 1.85030 \\
\hline 24.23366 & 1.607532 \\
\hline 22.41736 & 1.570889 \\
\hline 18.78201 & 1.569933 \\
\hline 17.44959 & 1.487543 \\
\hline 15.45549 & 1.36628 \\
\hline 11.28917 & 1.237122 \\
\hline 10.63391 & 1.18853 \\
\hline 8.784651 & 1.076398 \\
\hline
\end{tabular}

Tables6 and7represents the effect of storing time of modified Cellulase guar pastes for 1 day and two concentration of enzyme which were $0.5 \%$ and $1 \%$ concentration.

Cellulase enzyme was giving better viscosity compared with Cellulase enzyme $(0.5 \%)$ concentration. This may due to the cellulase enzyme with its action of hydrolyses can easily cause hydrolysis to guar chains while on high concentration of Cellulase $(1 \%)$ the hydrolysis part can react with the enzyme and cause spaces to decrease which in terms leads the voids to decrease in the modified guar gum which leads to increasing in the viscosity due to the tangle happened between the chains which is clear from table $(6,7)$ that there is a highly decrease in the viscosity after storing for one day only rather than the fresh paste as the viscosity decreased from (16.15578) poise at the rate of shear (6.779) to (1.850359) poise .when it stored for 1 day while guar gum was treating with Cellulase enzyme $(0.5 \%)$ concentration and the samples rotted after on day storage as mentioned before, and the apparent viscosity obviously decreased from (26.63942) poise to (1.85030) poise . The highly effect of storage on the modified Cellulase enzyme may be due to its action of hydrolysis which leads the reaction between the enzyme and breakage small chains are not stable and/or valid for more than even one day storage and hence these weak forces and tangle happened in the chains are not stable .Storage for few hours cause cracking and smashing for the tangled chains and hence cause rotting and loss in the apparent viscosity of the pastes.

Tables 8 and 9 represents the effect of storing time of

Table (8) the apparent Viscosity of the enzymatic modified Guar Gum with Brewer Yeast (1\%) conc. at different storage time (fresh, and 1day.

The Apparent viscosity of the Enzymatic modified Guar Gum with Brewer yeast (1\%).

\begin{tabular}{|c|c|}
\hline Fresh & 1day storage \\
\hline 6.911576 & 0 \\
\hline 6.175245 & 0 \\
\hline 5.476433 & 0 \\
\hline 5.276285 & 0 \\
\hline 4.888763 & 0 \\
\hline 4.317504 & 0.196043 \\
\hline 3.904006 & 0.175231 \\
\hline 3.665408 & 0.155344 \\
\hline 3.139866 & 0.149771 \\
\hline 2.677578 & 0.151311 \\
\hline 2.322676 & 0.138964 \\
\hline 2.085905 & 0.120128 \\
\hline
\end{tabular}

modified Brewer yeast guar pastes for 1 day and two concentration Of enzyme which were $1 \%$ and $3 \%$ Conc.

Table (9) the apparent Viscosity of the enzymatic modified

The Apparent viscosity of the Enzymatic modified Guar Gum with Brewer yeast( $3 \%$ ) conc.

\begin{tabular}{|c|c|}
\hline Fresh & 1day storage \\
\hline 0 & 0 \\
\hline 0 & 0 \\
\hline 0 & 0 \\
\hline 0 & 0 \\
\hline 0 & 0 \\
\hline 5.274194 & 0 \\
\hline 4.31928 & 0 \\
\hline 4.477181 & 3.104308 \\
\hline 4.02538 & 2.774063 \\
\hline 3.673099 & 2.811088 \\
\hline 3.136691 & 2.898749 \\
\hline 2.686871 & 1.104308 \\
\hline
\end{tabular}

Guar Gum with Brewer Yeast (3\%) conc. at different storage time (fresh and 1day)

It is clear from table ( 8 and 9 ) that both of the enzymatic 
modified Guar Gums with Brewer yeast (1\%) concentration is slightly higher than $(3 \%)$ concentration.

The apparent viscosity of the $(1 \%)$ concentration was (6.911576) poise and at $(3 \%)$ concentration the apparent viscosity was (5.274194) poise. But whether it was fresh or stored the viscosity was very low while modifying guar gum with brewer yeast. This may be due to the hydrolysis actions of the three types of enzymes which were (lipase, protease, and amylase) that Brewer yeast contains.as they are all classified as a hydrolysis enzymes.

Hydrolysis enzymes catalyze reactions that involve hydrolysis. This cases usually involves the transfer of functional groups to water. When the hydrolase acts on amide, glycosyl, peptide, ester, or other bonds, they not only catalyze the hydrolytic removal of a group from the substrate but also a transfer of the group to an acceptor compound. These enzymes could also be classified under transferases since hydrolysis can be viewed as a transfer of a functional group to water as an acceptor ${ }^{(10)}$.A Proteolytic enzyme, also called protease, proteinase, or peptidase, any of a group of enzymes that break the long chainlike molecules of proteins into shorter fragments (peptides) and eventually into their components, amino acids (11)A lipase is any enzyme that catalyzes the hydrolysis of fats (lipids). Lipases are a subclass of the esterases ${ }^{(12)}$. Amylase, any member of a class of enzymes that catalyze the hydrolysis (splitting of a compound by addition of a water molecule) of starch into smaller carbohydrate molecules such as maltose (a molecule composed of two glucose molecules) ${ }^{(13)}$.

So modifying with Brewer yeast was found to be more difficult and as a result of hydrolysis actions which may be occurred due to the mixing of three types of hydrolysis enzyme together and hence Guar gum with its ratio of 1:2 galactose to mannose ratio was not preferred to be modified by either Brewer yeast not Cellulase enzyme.

\section{Conclusion:}

In present work the enzymatic modification of galactomannan gums which extracted from Guar gum depolymerized by cellulase enzyme which classified as hydrolysis enzymes was compared to a native Guar gum and studying rheological properties were studied.

It seems from the rheogrames that the modification of Guar doesn't affect the rheological properties of both native and modified Guar gum. They are all characterized by nonNewtonian pseudo plastic.Depolymerization enzymatic modification using Cellulase enzyme decrease the apparent viscosity of the Guar gum while oxidiation enzymatic modification using laccase enzyme increases viscosity.

The apparent viscosity increases while using laccase enzyme with (2\%) concentration rather than (4\%) concentration. And as it mentioned before that Laccase enzyme is one of the (oxidoreductose enzymes) which cause an oxidation to the paste and convert it from viscous polysaccharide solution into elastic gel. this is due to the carbonyl groups which generated by the enzymatic reaction which eventually form hemiacetal bonds between generated carbonyl group and free $\mathrm{OH}$ groups causing internal crosslinking of Guar gum and their structuring to yield elastic gels.
The apparent viscosity of using Cellulase enzyme with both concentrations $(0.5 \%, 1 \%)$ in the modification of Guar gum have been decreased compared with the native gum. The decrease in apparent viscosity maybe due to the breakage of chains and a cleavage of the peptide bonds and the larger molecules are broken down to smaller ones, this type of enzymatic modification would be a depolymerization enzymatic modification, causes to a various extent decreasesing in the apparent viscosity of the Guar Gum.

The apparent viscosity of using Brewer yeast with both concentrations $(1 \%, 3 \%)$ in the modification of Guar gum have been decreased compared with the native gum this phenomena may be due to the Brewer Yeast contains three types of hydrolysis enzymes (amylase, protease, and lipase) and this enzymes may cause hydrolysis actions which increase solubility.

While studying the effect of storage time as the samples stored for (fresh, 1day and 7 days).

It seems that the storage doesn't affect the rheological properties as that all examined pastes using (Cellulase and laccase ) enzyme as well as Brewer yeast they are all still described by non- Newtonian pseudoplastic.

The storage time decrease the viscosity after storing the paste for (one day and 7 days), But whether it was fresh or stored the viscosity was very low while modifying guar gum with both Brewer yeast and Cellulase enzyme.

Guar gum with its ratio of 1:2 galactose to mannose ratio was not preferred to be modified by either Brewer yeast not Cellulase enzyme.

\section{REFERENCES}

[1] V.Mathur and N.K .Mathur, "Fenugreek and other lesser known legume galactomannan polysaccharides scope for development", Journal of science and industrial research, Vol.54, 475-481, July 2005.

[2] A.Hebeish, "development in textile chemistry and chemical technology, 2nd ED, academy of scientific research and technology", 1994.

[3] D.Dentini, M.Ceriscenzi,"Guar gum methyl ethers, part1, synthesis and macromolecular characterization, polymer" Vol.46, 12247-12255, Dec.2005.

[4] Yves.M.Galante,Tiziana.Silvetti,Luca.Merlilni,paola.Campia“Enzyme oxidation of plant galactomannans yielding biomaterials with novel properties and applications, including as delivery systems", June2018.

[5] M.Mola, S.Z.A.Mousa, G.H.Ramdan, "Chemical modification of galactomannan gum extracted from fenugreek seeds via oxidation with H $2 \mathrm{O} 2$ and its utilization in textile printing", Nov.2008

[6] M.Turker, "yeast Biotechnology diversity and application", conference paper, April.2014.

[7] C.J.Rodgers,C.F.Blanford1,S.R.Giddens,P.Skamnioti, thetypeof enzymatic, "Designer laccases: a vogue for high-potential fungal enzymes", Volume 28, Issue 2, Pages 63-72,February 2010.

[8] D.mudgil,S.Barak,B.S.Khatkar,'X- ray diffraction ,IR Spectroscopy and thermal characterization of partially hydrolyzed Guar gum, international journal of biological macro molecules, optimization of enzymatic hydrolysis of guar gum using response surface methodology, Journal of food and science technology,2012.O. Young, "Synthetic structure of industrial plastics (Book style with paper title and editor)," in Plastics, 2nd ed. vol. 3, J. Peters, Ed. New York: McGraw-Hill, 1964, pp. 15-64.

[9] D.Mudigil,S.Barak,B.S.Khatkar,'Effect of enzymatic depolymerization on physiochemical and rheological properties of guar gum”,Carbohydrate polymer,Vol. 90 ,p.224-228,2012.

[10] https://en.m.wikibooks.org/wiki/Structural_Biochemistry/Specific_En zymes_and_Catalytic_Mechanisms/Enzyme_Classification

[11] https://www.britannica.com/science/proteolytic-enzyme

[12] https://en.wikipedia.org/wiki/Lipase

[13] https://www.britannica.com/science/amylase 